\title{
MINIMAL ACCESS SPINAL TECHNOLOGIES (MAST) FUSION PROCEDURES FOR THE TREATMENT OF THE DEGENERATIVE LUMBAR SPINE
}

(A PART OF MULTICENTRAL PROSPECTIVE STUDY)

\author{
Khoshab AH ${ }^{1}$, Durny $\mathrm{P}^{1}$, Kolarovszki $\mathrm{B}^{2}$.
}

${ }^{1}$ Department of Neurosurgery, Central Military Hospital, Ružomberok, Slovakia

${ }^{2}$ Clinic of Neurosurgery, Jessenius Faculty of Medicine in Martin, Comenius University in Bratislava, University Hospital Martin, Slovakia

\begin{abstract}
A b s t r a c t
A prospective multicentral observational study of minimally invasive fusion to treat degenerative lumbar disorders, and to report outcomes of one or two level minimally invasive posterior lumbar interbody fusion (MLIF) for degenerative lumbar disorders in a multi-center 1-year prospective study. We prospectively studied a group of 32 patients, mostly female 24 ( $75 \%$ female ), and 8 males ( $25 \%$ ). They underwent minimally invasive transforaminal lumbar interbody fusion (mTLIF), 21 of them monosegmental and 11 bisegmental. Patients demographics, intraoperative data and complications were recorded. Time to first ambulation, time to study-defined recovery, surgical duration, blood loss, fluoroscopy time and adverse events were recorded. Visual analogue scale (VAS) of back and legs pain, Oswestry disability index (ODI) and health-related questionnaire (EQ-5D) were assessed preoperatively and at defined time points through 12 months postoperatively. Mean surgical duration, blood loss and intraoperative fluoroscopy time were 125 vs. 175 minutes, 150 vs. $170 \mathrm{ml}$, and $105 \mathrm{vs} .145$ seconds in one- and twolevel segments, respectively. Mean preoperative VAS back (6.5) and VAS leg (7.9) scores dropped significantly ( $\mathrm{p}<0.0001)$ to 3.5 (2.6) and 2.1 (2.0) at discharge (6 weeks). At the end, this is the largest prospective multi-center observational study of MLIF to date, following routine local standard of practice and, MLIF demonstrated favourable clinical results with early and sustained improvement in patient reported outcomes and low major perioperative morbidity.
\end{abstract}

Key words: Degenerative disc disease, minimally invasive posterior lumbar interbody fusion, transforaminal lumbar interbody fusion

Abbreviations:

ALIF
DDD
MAST
MLIF
MTLIF
ODI
PLIF
TLIF
VAS

Anterior Lumbar Interbody Fusion

Degenrative Disc Disease

Minimal Access Spinal Technologie

Minimally Invasive Lumbar Interbody Fusion

Minimally Transforaminal Lumbar Interbody Fusion

Oswestry Disability Index

Posterior Lumbar Interbody Fusion

Transforaminal Lumbar Interbody Fusion

Visual Analog Scale

\section{INTRODUCTION}

Instrumented lumbar fusion is the gold standard for the management of lumbar degenerative disc disease (DDD) and it is usually done through an open procedure, which involves an excessive intraoperative dissection [17] and retraction of the paraspinal musculature leading, in a short term basis, to a prolonged recovery time from the surgery [1].

Corresponding a u thor:

A. Hamid Khoshab, M.D., Department of Neurosurgery, Central Military Hospital, Gen. Miloša Vesela Str. N. 21, 034 26, Ružomberok, Slovakia

e-mail: Hamidko78@gmail.com 
The open approach is frequently associated with the significant blood loss and need of transfusion, produces the majority of the perioperative pain, increases hospital stay and the chances of infection and delays the return to normal activities and to work [1,2]. In a long term basis, the open procedure leads to denervation, atrophy and loss of the muscles independent function, resulting in an increased risk of fusion disease, a term that has been coined to describe its occurrence $[6,11,12]$.

Over the past decades minimal invasive surgery is gaining popularity in the treatment of DDD [19]. The minimally invasive spinal (MIS) surgery was developed as a potential solution to the above mentioned problems by reducing the amount of iatrogenic soft tissue injury while reaching the same traditional goals of the open procedures. Besides minimizing the long term effects of exposure-related muscle injury [11, 12], minimally invasive lumbar fusion techniques hold the promise of immediate short-term advantages [14, 15].

The minimally invasive access requires a surgical corridor targeted on the disease which is accomplished by using a series of tubular muscle dilators allowing a clear intraoperative visualization to perform these procedures together with the parallel use of image guided percutaneous insertion of pedicle screws and instrumentation.

\section{METHODS}

32 patients participated in this study at our department, were those that have indication for a single or double level instrumented lumbar fusion for the treatment of the degenerative lumbar spinal pathologies causing back pain and/or leg pain.

Approximately 200 patients from 19 centers located in Europe, Australia and Canada were enrolled over a period of 12 months. From June 2011 to June 2012, in our neurosurgical unit we were prospectively studied a cohort of 32 patients ( 24 females, 8 males) with the mean age of 53 years who fulfilled the inclusion criteria at the primary consultation, were included in the study.

Schedule for patient follow-up visits were after surgery at 4 weeks ( \pm 2 weeks), 3 months ( \pm 1 month), 6 months $( \pm 1$ month) and 12 months ( \pm 2 month). Preoperative data included registration of patient demographics which contain visit date, sex of patients, weight and height with calculating of body mass index (BMI), work status, medical history which include approximately duration of symptoms that resulted in the planned surgery, how long the patient has been treated with the conservative care and has the patient had any previous lumbar spine surgery(ies).

Only microdiscectomy was allowed to be included. Patients examined whether they had any neurological deficit or either pre-existing medical conditions relevant to the study. The average and types of pain medications which were taken before and after surgery were also documented. Imaging performed for diagnostic reasons includes X-ray (native \& dynamic) and MRI scans.

The main reason for surgery were divided into the back pain, legs pain with or without neurologic dysfunction and neurologic claudications as it is shown in graph below. The
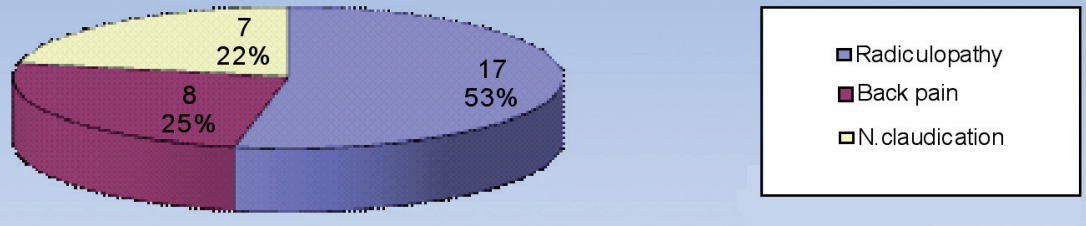

Graph 1 Indication for surgery 
main pathology(ies) at the level to be operated were spondylolisthesis (degenerative, isthmic), stenosis either central or foraminal and disc pathology (disc height reduction, disc herniation).

If another level going (only 2 levels included) to be treated, the same questions were fulfilled.

\section{RESULTS}

From June 2011, until June 2012 we prospectively studied group of 32 patients mostly female 24 ( 75\% female ), and 8 males with mean age 53 years, mean BMI 26, and mean duration of symptoms were 15 month.

They underwent mTLIF (Fig.1), 21 of them monosegemental and 11 bisegemental. Segments which mostly were treated were L4/5 and L5/Sl, only 4 patients underwent surgery at L3/4. Patients were indicated for surgery mostly for the leg pain (53\%), back pain $(25 \%)$ and neurogenic claudication (22\%). They were treated for degenerative pathologies mostly disc pathology (72\%) with or without spinal stenosis, and or (28\%) spondylolistheis. $22 \%$ of patients had previous decompression surgery at the target level.
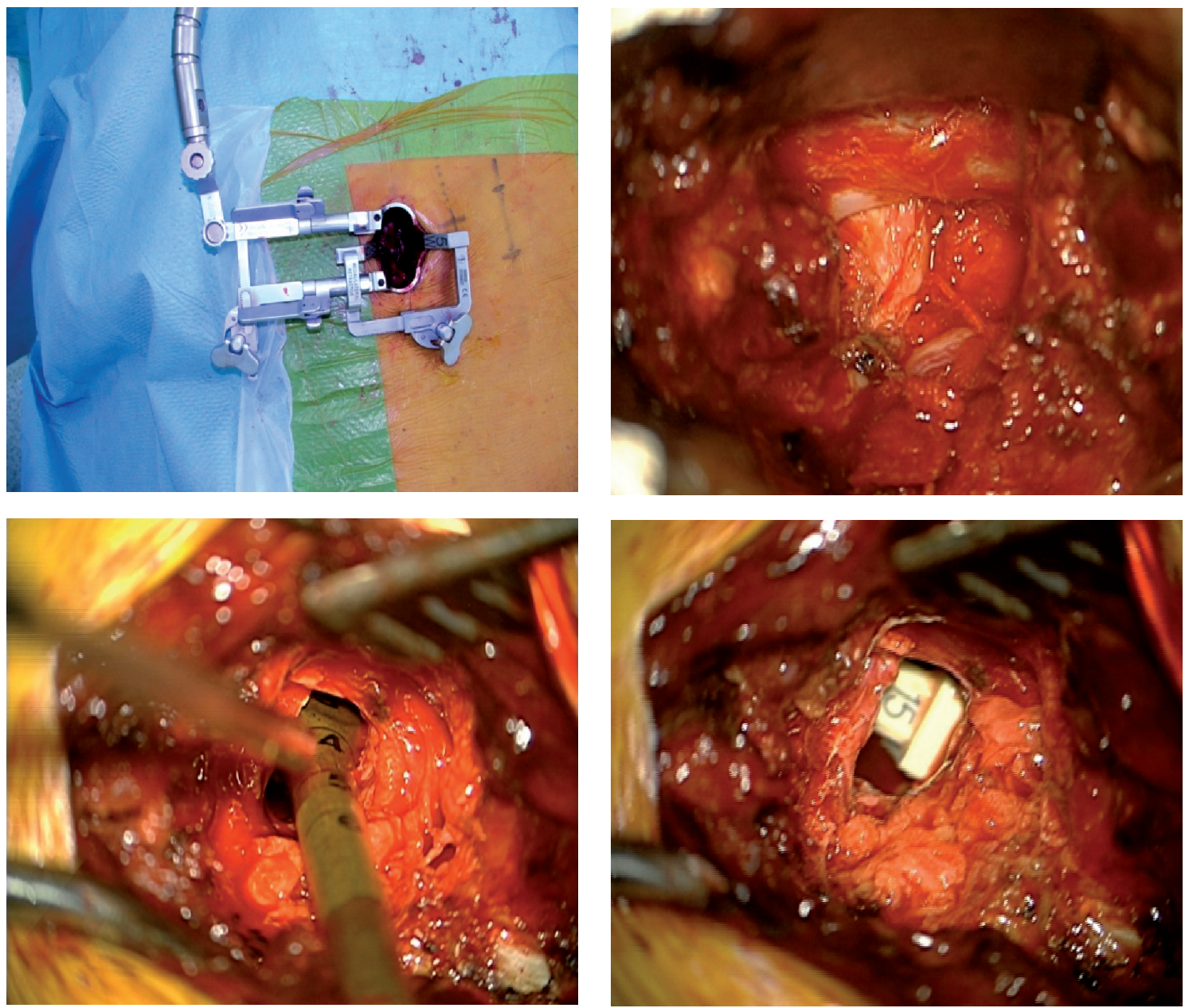

Fig. 1 Perioperative illustration of mTLIF using MAST tubular distractors. 
Mean surgical duration, blood loss and intraoperative fluoroscopy time were 125 vs.175 minutes, 150 vs. $170 \mathrm{ml}$, and 105 vs. 145 seconds in one- and two-level cases, respectively. (Table 1)

Table 1. Intraoperative blood loss, fluoroscopy time and surgical duration

\begin{tabular}{|l|c|c|}
\hline & One level & Two levels \\
\hline Blood loss & $150 \mathrm{ml}$ & $170 \mathrm{ml}$ \\
\hline Duration of surgery & $125 \mathrm{~min}$. & $175 \mathrm{~min}$. \\
\hline Intraoperative flouro-time & $105 \mathrm{sec}$. & $145 \mathrm{sec}$. \\
\hline
\end{tabular}

The mean time to the first ambulation was 1.5 days, and time to study-defined recovery was 3.0 days. Mean preoperative VAS back (6.5) and VAS leg (7.9) scores dropped significantly $(\mathrm{p}<.0001)$ to $3.5(2.6)$ and $2.1(2.0)$ at discharge (6 weeks).All of patients were available at follow-up schedules. One-level surgery occurred at L4-5 or L5-S1 in 66\% and twolevel surgery at L4-S1 in 34\%.VAS improvement was sustained between 6 weeks and final follow-up at 12 months. Preoperative ODI (58) and EQ5D (51.5) changed to 36.5 (22) and 68.6 (72.1) at 4 weeks. (12 months) (p<.0001). 56\% of patients were working at the baseline , the rest were not working either because of spine problem or were at maternal holidays, or were pensioners. From above 18 patients, 67\% return to their works at 6 month follow up and rest of them which were mostly elderly had to find part - time jobs. In the 12 month follow up, a total of 1 adverse events in 2 patients (6\%) were attributed to the hardware (screw breakage), no deep surgical site infections or other complication were seen. (Table 2)

Table 2. Preoperative and follow up questionairies results (NE-Not Evaluated)

\begin{tabular}{|l|c|c|c|c|}
\hline & Preop. & Postop. & 6 weeks & 12 month \\
\hline VAS (back) & 6.5 & 3.5 & 2.6 & 2.2 \\
\hline VAS (leg) & 7.9 & 2.6 & 2.0 & 2.0 \\
\hline ODI (\%) & 58 & NE & 36.5 & 22 \\
\hline EQ5D & 51.5 & NE & 68 & 72.1 \\
\hline
\end{tabular}

\section{DISCUSSION}

Our study presents outcome and complication rates after mTLIF surgery from june 2011 to 2012 in the Central Military hospital, Ružomberok, Slovakia, as a part of multi-center study. At the end of the study, 225 patients were available at 12 months. VAS improvement was sustained between 4 weeks and final follow-up at 12 months. Preoperative ODI (45.5) and EQ5D VAS (52.9) changed to 34.5 (23.2) and 65.4 (70.1) at 4 weeks (12 months) $(p<0.0001)$.In the 4-week time window, a total of 39 adverse events in 32 patients $(12.7 \%)$ were attributed to surgery, approach or device; no deep surgical site infections and one revision surgery were observed. The experience with the minimally invasive lumbar fusion procedures are documented in the medical literature. Foley et al [4] in a review article conclu- 
ded that the preliminary clinical results (of ALIF, TLIF and PLIF) suggest that minimally invasive lumbar fusion will have a beneficial impact on the care of patients with spinal disorders. Because the techniques are new and evolving, studies with long-term follow-up will be necessary to validate its success and support their potential benefits. Park and Foley [14] describe a technique for minimally invasive TLIF that permits the surgeon to reduce spondylolisthesis percutaneously. The results in 40 consecutive patients who underwent minimally invasive TLIF for symptomatic spondylolisthesis utilizing this approach were reviewed. The authors conclude that minimally invasive TLIF for symptomatic spondylolisthesis appears to be an effective surgical option with results that compare favorably to open procedures. Schizas et al [19] published their TLIF initial experience both with minimally invasive and open procedures in 36 patients, 18 in each group with an average follow-up of 22 and 24 months, respectively. Clinical outcome was assessed using the VAS and the Oswestry disability index. There was no difference in length of surgery between the two groups. The minimally invasive TLIF group resulted in a significant reduction of blood loss and had a shorter length of hospital stay.No difference was observed in postoperative pain, initial analgesia consumption, VAS or ODI between the groups. Three pseudoarthroses were observed in the minimally invasive TLIF group however, not statistically significant. A steeper learning effect was observed for the minimally invasive TLIF group. O'Toole et al [13] published a retrospective review of prospectively collected databases of 1274 consecutive patients that underwent 1338 minimally invasive spinal surgeries performed by the authors. The postoperative infection rates were $0.74 \%$ for instrumented arthrodesis and $0.22 \%$ for the entire cohort series. Their findings suggest that minimally invasive techniques reduce postoperative wound infections by as much as 10-fold compared with other large, modern series of open spinal surgery in the literature. Although the published literature shows evidence of the benefits of the minimally invasive lumbar fusion procedures over the traditional open technique the results do not allow a final conclusion due to the lack of data from a sufficient number of patients.

\section{CONCLUSIONS}

It was the largest prospective multi-central observational study of MLIF to date, following routine local standard of practice. MLIF demonstrated favourable clinical results with early and sustained improvement in patient reported outcomes and low major perioperative morbidity.

Based on our results and clinical experiences we can put forward the following conclusions: 1. Mininvasive fusion surgery is muscle friendly surgery which is preventing the postoperative fusion disease.

2. In polymorbid and obese patients MLIF reduces the blood loss and major complications which is sometimes crucial and life saving for the patient.

3. Less hospital stay, analgesic usage and early comeback to the previous work.

4. Fluoroscopy time is depending on the learning curve of the surgeon and could minimize in the era of $3 \mathrm{D}$ imaging and navigation.

\section{REFERENCES}

1. Bagan B, Patel N, Deutsch H. Perioperative complications of minimally invasive surgery (MIS): comparison of MIS and open interbody fusion techniques.Surg Technol Int. 2008; 17:281-286.

2. Dhall SS, Wang MY, Mummaneni PV; Clinical and radiographic comparison of mini-open transforaminal lumbar interbody fusion with open transforaminal lumbar interbody fusion in 42 patients with long-term followup. J Neurosurg Spine 2008: 9560-565.

3. Djurasovic M, Bratcher KR, Glassman SD.The Effect of Obesity on Clinical Outcomes After Lumbar Fusion. Spine 2008; 16: 1789-1792. 
4. Foley KT, Holly LT, Schwender JD. Minimally Invasive Lumbar Fusion. Spine 28:S26-S35, 2003.

5. Gavaskar AS, Achimuthu R. Transfacetal fusion for low-grade degenerative spondylolisthesis of the lumbar spine: results of a prospective single center study. J Spinal Disord Tech., 2010; 127-156.

6. Gejo R, Matsui H, Kawaguchi Y.Spinal changes in trunk muscle performance after posterior lumbar surgery. Spine 1999;24:1023-8.

7. German JW, Foley KT. Minimal Access Surgical Techniques in the Management of the Painful Lumbar Motion Segment. Spine 2005; 30:S52-S59.

8. Haruštiak S.Princípy chirurgie II, 1 vydanie Bratislava, SAP 2010; s.270-290 review.

9. Kahanovitz N, Viola K, Gallagher M. Long-term strength assessment of postoperative discectomy patients. Spine 1989;14:402-3.

10. Kawaguchi Y, Matsui H, Tsuji H. Back muscle injury after posterior lumbarspine surgery: a histologic and enzymatic analysis. Spine 1996;21:941-4.

11. Kawaguchi Y, Matsui H, Tsuji H. Back muscle injury after posterior lumbar spine surgery: 2. Histologic and histochemical analyses in humans. Spine 1994;19:2598-602.

12. Mayer TG, Vanharanta H, Gatchel RJ. Comparison of CT scan muscle measurements and isokinetic trunk strength in postoperative patients. Spine. 1989;14:33-36.

13. O’Toole JE, Eichholz KM,Fessler RG; Surgical site infection rates after minimally invasive spinal surgery. J Neurosurg Spine 2009, 11:471-476.

14. Park P, Foley KT; Minimally invasive transforaminal lumbar interbody fusion with reduction of the spondylolisthesis: technique and outcomes after a minimum of 2 years' follow-up. Neurosurg Focus 2008; 25 (2):E16.

15. Park Y, Ha JW. Comparison of One-Level Posterior Lumbar Interbody Fusion Performed With a Minimally Invasive Approach or a Traditional Open Approach. Spine 2007;32:537-543.

16. Patel N, Bagan B, Vadera S.Obesity and spine surgery: relation to perioperative complications. J Neurosurg Spine. 2007; 6: 291-297.

17. Rantanen J, Hurme M, Falck B. The lumbar multifidus muscle five years after surgery for a lumbar intervertebral disc herniation. Spine 1993;18:568-74.

18. Scheufler, Dohmen H, Vougioukas VI. Percutaneous. Transforaminal Lumbar Interbody Fusion for the Treatment of Degenerative Lumbar Instability. Neurosurgery 2007;60(ONS Suppl 2):ONS-203-ONS-213.

19. Schizas C, Tzinieris N, Tsiridis E.Minimally invasive versus open transforaminal lumbar interbody fusion: evaluating initial experience. International Orthopaedics (SICOT) 2008.

20. Schwender JD, Holly LT, Rouben DP.Minimally Invasive Transforaminal Lumbar Interbody Fusion (TLIF). Spinal Disord Tech 2005; 18:S1-S6.

21. Seok JB, Sang-Ho Lee, Jin-Sung Kim, Byungjoo Jung, Gun Choi.Adjacent segment degeneration after lumbar interbody fusion with percutaneus pedicle fixation for adult low grade isthmic spondylolisthesis: minimum 3 y FU, j.neurosurgery 2010;67:1600-1608.

22. Villavicencio AT, Burneikiene S, Bulsara KR et al; Perioperative Complications in Transforaminal Lumbar Interbody Fusion Versus Anterior-Posterior Reconstruction for Lumbar Disc Degeneration and Instability. J Spinal Disord 2006; 19: 92-97.

Received: April, 4, 2014

Accepted: April, 30, 2014 


\section{INFORMATION ABOUT THE PUBLISHER AND THE JOURNAL}

PuBlisher: Comenius University, Jessenius Faculty of Medicine in Martin Address: 03601 Martin, Mala Hora Str. N. 4A, Slovakia IČO: 00397865

PERIODICITY: three times per year YEAR of issuance: 14th AMM 14/1 was issued in May 2014

\section{INSTRUCTIONS TO AUTHORS FOR MANUSCRIPTS SUBMITTED TO ACTA MEDICA MARTINIANA}

Acta Medica Martiniana (AMM) publishes original papers (in extenso and short - rapid communications) as well as review articles of high quality from medical and biomedical sciences and from nursery, which have not been published yet, and will not be submitted for publication elsewhere. The papers are published in English, non-native English authors are responsible for the translation. The AMM is open access journal in print and online versions (http://www.degruyter.com/view/j/acm, + 